\title{
SILENT CRIES: ATTITUDES AND PROBLEMS OF TEACHERS TEACHING MTB-MLE IN PUBLIC SCHOOLS
}

\author{
Mary Grace Yap-Dequiña Phd ${ }^{1}$, Elleine Rose A. Oliva, EdD ${ }^{2}$
}

Article DOI: https://doi.org/10.36713/epra9386

DOI No: 10.36713/epra9386

\begin{abstract}
The purpose of this phenomenological study was to elicit teachers' lived experiences of teaching Mother Tongue-Based Multilingual Education (MTB-MLE) and its use as a medium of instruction in several primary subjects. Additionally, it seeks to understand the strategies employed in resolving problems and generating knowledge for the academic community. It used a snowball sampling technique to select six (6) teachers for in-depth interviews (IDIs) and five (5) teachers for focus groups with eleven (11) teachers from the region's five (5) public schools. Four (4) significant themes emerged from the participants' attitudes and problems regarding the following: significant challenges in teaching MTB-MLE, difficulty understanding terminology, language use confusion, and translation challenges. Four (4) primary themes emerged in their strategies: translation, the use of additional instructional materials, the use of technology, and consultation with other teachers. Finally, three (3) significant themes were shared for their insights and knowledge, including the importance of MTB-MLE in student learning, the need for instructional materials development, and teacher readiness to teach. The findings of this study are critical for academic institutions to understand how teachers teach MTB-MLE daily.
\end{abstract}

KEYWORDS: MTB-MLE, public teacher, problem, strategy, knowledge, phenomenological, thematic analysis, Region XI, Philippines

\section{INTRODUCTION}

The Department of Education has taken measures to raise the bar for educational quality in the Philippines. Various ethnolinguistic groups speak over 170 languages affects education (Llaneta, 2018). As a result, from Kindergarten to third grade, Mother Tongue-Based Multilingual Education (MTB-MLE) was adopted as the medium of instruction to enhance and ensure learning outcomes (DepEd, 2012). It is not unusual for a primary school teacher to have students with various linguistic backgrounds. The difficulty is in properly implementing it on the path to the desired Mother Tongue (Gempeso \& Mendez, 2021). Teachers are responsible for developing the Mother Tongue curriculum and instructional materials. The primary difficulty faced by teachers when teaching MTB-MLE is a dearth of instructional materials such as textbooks, dictionaries, and references (Tupas, 2017).

According to UNESCO (2016), $40 \%$ of the global population does not have education in a language they understand. Numerous studies revealed a variety of difficulties in implementing MTB-MLE. Despite the promise of rich language development, Japan's language curriculum requires improvement, including strengthening the organization's structure and enhancing MTB-MLE teaching cohesion (Ohyama, 2018). In Cambodia, leadership, resources, and input from non-dominant language speakers are frequently missing from curriculum planning, resulting in numerous gaps in MTB-MLE implementation (Ball \& Smith, 2021).

Even with the mandatory implementation of the MTB-MLE program in the Philippines, teachers encountered difficulties teaching and received negative feedback about the program's current performance, which is why English is still used as the primary language of instruction (Velez et al. 2019). It is critical to study the challenges educators face like a bridge to the successful implementation of the MTB-MLE program to respond to students' need to learn by using the materials as a springboard for learning a familiar language (Balacano, 2020). Thus, teachers play a 
critical role in developing educational programs that incorporate proposed curriculum reforms and emphasize student learning, particularly MTB-MLE (Bacalla, 2020). This study elucidates the attitudes toward and difficulties associated with teaching MTBMLE. The findings provide academics with answers, techniques, and insights.

\section{OBJECTIVES}

The purpose of this study is to describe the lived experiences of public school teachers, specifically their attitudes and problems about teaching the implemented MTB-MLE and its daily use as a medium of instruction in other subjects. The study results will significantly impact the implementation of MTB-MLE at primary levels.

\section{METHODS}

This is a qualitative study that employs a phenomenological approach. Qualitative research aims to elicit information about an individual's life experience during an event. Additionally, it seeks meaningful information from participants who have encountered the issue and fully comprehends shared experiences, particularly shared opinions or attitudes (Creswell, 2016).

Participants included educators from various public schools throughout Region XI. Additionally, participants were selected for this study using the snowball sampling technique, which included inclusion criteria. The following guidelines have been established: a) public school teachers in Region XI; b) teachers of MTB-MLE in any grade level from Kindergarten to third grade in Region XI; and c) teachers with a minimum of three years experience teaching MTB-MLE.

The primary source of data for this qualitativephenomenology investigation was qualitative interviews. In-depth interviews (IDIs) with six (6) participants and focus group interviews (FGDs) with a group of five (5) interviewees were used as data sources in this study. Eleven (11) participants were used in the data collection technique. In-depth interviews (IDI) and focus group discussions were used to collect reliable and rich data for the results and discussion (FGD).

\section{RESULTS AND DISCUSSION}

\section{Table 1}

Key Themes and Ideas on the Attitudes and Problems of Teachers Teaching MTB-MLE in Public Schools and their Use as a Medium of Instruction in other subjects.

\begin{tabular}{|l|l|}
\hline \multicolumn{1}{|c|}{ Major Themes } & \multicolumn{1}{c|}{ Core Ideas } \\
\hline \multirow{4}{*}{ Challenges in Teaching } & $\begin{array}{l}\text { - Difficulty in teaching MTB-MLE, especially in the early years of } \\
\text { implementation. } \\
\text { Organization }\end{array}$ \\
- Many teaching adjustments have taken place because of teaching different \\
languages. \\
- Difficulty in sharing class lessons because of not being used to Sinugbuanong \\
Binisaya. \\
- Undergoing a decisive adjustment in teaching MTB-MLE. \\
- The need of studying hard on the MTB-MLE lessons than other subjects \\
because it is necessary to understand the meaning of the words to be explained \\
clearly to the students to avoid confusion.
\end{tabular}




\begin{tabular}{|l|l|}
\hline & $\begin{array}{l}\text { - There are confusion and difficulty in teaching students with other ethnic } \\
\text { languages, such as B'laan, Manobo, and Muslim. They even find it challenging } \\
\text { to understand English and Filipino languages. }\end{array}$ \\
\hline $\begin{array}{l}\text { - Feeling of difficulty in using Sinugbuanong Binisaya in areas with ethnic } \\
\text { groups. Translations into B'laan, Filipino and English, are required to make the }\end{array}$ \\
lessons understandable. \\
$\begin{array}{l}\text { - Very challenging to have Muslim students who do not even understand Bisaya. } \\
\text { - It is very challenging to make students understand the lessons, especially those } \\
\text { from other places such as Pigcawayan, where their familiar languages are } \\
\text { Ilonggo and Tagalog. }\end{array}$ \\
\hline
\end{tabular}

Attitudes and Problems of Teachers Teaching MTBMLE in Public Schools and Its Use as a Medium of Instruction in few subjects.

Gathered from the responses of the participants, the following were the major themes that emerged: (1) challenges in teaching organization, (2) difficulty in understanding terminology, (3) confusion in the use of languages, and (4) translation challenges.

\section{Challenges in Teaching Organization}

Teachers encountered difficulties teaching MTB-MLE lessons, mainly when unfamiliar language was used. They have difficulty communicating in Sinugbuanong Binisaya, a dialect of the Cebu language. Organizing instruction is challenging due to the students' unfamiliarity with another language. Sumalinog (2018) reported that teachers have difficulty utilizing the teaching aids because the terms used are not locally translated. Additionally, Dumetz et al. (2021) discovered that those with concurrent languages encountered challenges and found the lessons more challenging to comprehend. The latter statement substantiated one of the participants' challenges.

\section{Difficulty in Understanding Terminologies}

Complicated terminologies used in Sinugbuanong Binisaya teaching materials, such as books, present the most challenging issue for students and teachers, as it is not their native language. Gaylo (2020) demonstrated that the limited vocabulary makes implementing MTB-MLE goals difficult. Certain students may have limited comprehension of the language being used. Adriano et al. (2021) identified several difficulties, such as a lack of textbooks and dictionaries, that made it particularly difficult to teach and achieve immediate success with MTB-MLE implementation, as teachers are unfamiliar with the terminology used. For instance, Kolman (2019) discovered that teachers instructing students in
Mathematics using MTB-MLE find the textbook's content challenging to teach due to its use of complex terminologies. Additionally, they must translate the elaborate terms used to aid students in comprehending the lessons.

\section{Confusion in the Use of Languages}

Medilo (2016) revealed that the MTB-MLE curriculum welcomes additional challenging tasks for teachers. Asfaha (2020) considered language as an essential factor in learning. Sinugbuanong Bisaya is not familiar to the ordinary people or other ethnic groups in Davao Region. The confusing experience of mixing languages is predominant to them. MTB-MLE as a subject and even as a medium of instruction, particularly in public schools, has confused language teaching. Teachers experienced confusion in the use of languages taught to students. Teachers and students found it easier to teach or learn Filipino or English because they are already using those languages at home or school. Adding MTB-MLE makes teaching and learning difficult. Hence, MTB-MLE becomes a barrier rather than a bridge for learning.

\section{Translation Challenges}

Tonio and Ella (2019) discussed the difficulties encountered when translating technical terms in MTB-MLE, such as in Science and Mathematics subjects. Teachers can use translation to help students make intricate connections between their experiences outside and even inside the classroom. However, the region's use of Sinugbuanong Binisaya has unfamiliar or complicated terminologies, posing translation difficulties for a few students from different ethnic groups in the class. As a result, Abrea et al. (2020) stated that students have difficulty comprehending lectures, which challenges teachers' translation abilities. 
Table 2

Key Themes and Ideas on Strategies or Techniques used by Teachers to Overcome the Problems Encountered in Teaching MTB-MLE

\begin{tabular}{|c|c|}
\hline Major themes & Core Ideas \\
\hline Translation of Terminologies & $\begin{array}{l}\text { - Using translation to understand difficult words and lessons. } \\
\text { - Using English dictionaries to easily translate words and to make } \\
\text { students understand. } \\
\text { - Translating complex terminology using students' familiar vocabulary. }\end{array}$ \\
\hline $\begin{array}{l}\text { Utilization of other Instructional } \\
\text { Materials }\end{array}$ & $\begin{array}{l}\text { - Using words with pictures to make it easier to understand. Like } \\
\text { storybooks written in MTB-MLE. } \\
\text { - Using the English Dictionary makes it easier to give the equivalent word } \\
\text { in Sinugbuanong Binisaya and develop the vocabulary. } \\
\text { - Using concrete examples such as objects, animals, etc, to encourage } \\
\text { active interaction and quick comprehension of the lessons. }\end{array}$ \\
\hline Use of Technology in Teaching & $\begin{array}{l}\text { - Letting students enjoy learning MTB-MLE by using video clips and } \\
\text { multimedia presentations. } \\
\text { - Using Multimedia such as Powerpoint presentations. } \\
\text { - Valuing the use of technology and other strategies as an effective means } \\
\text { of addressing the challenges of MTB-MLE teaching. }\end{array}$ \\
\hline Consultation with Another Teacher & $\begin{array}{l}\text { - Seeking advice, help, and asking questions from fellow teachers with } \\
\text { vast experience in teaching MTB-MLE. } \\
\text { - Collaborating and consulting fellow teachers is an effective method for } \\
\text { them }\end{array}$ \\
\hline
\end{tabular}

Strategies or Techniques used by Teachers to Overcome the Problems Encountered in Teaching MTB-MLE

The following significant themes appeared based on the responses of the participants: (1) translation of terminologies, (2) utilization of other instructional materials, (3) use of technology in teaching, and (4) consultation with another teacher.

\section{Translation of Terminologies}

There are difficulties in translating Sinugbuanong Binisaya into student-friendly terms. However, teachers of MTB-MLE frequently used translation as a strategy to aid in comprehension during lessons. Teachers who borrow and translate materials from one language to another improve students' comprehension of the lessons (Kolman, 2019). The translation is significant because it can assist in meeting the needs of students who speak a variety of languages. Maeikien (2019) and Parba (2018) emphasized that translation answers all teachers' challenges when teaching MTB-MLE. The translation is highly beneficial in learning using the students' native language because it links the students and the lesson.

\section{Utilization of other Instructional Materials}

Another effective strategy is to incorporate instructional materials into the MTB-MLE curriculum. Teachers utilize MTB-MLE storybooks that students can utilize. Students demonstrate literary appreciation, mastery, and comprehension of the material's content. Additionally, using a familiar language makes learning much more accessible. As a result, instructional materials' shortcomings require attention and correction, as students and teachers rely on these tools to acquire knowledge. Teachers of MTB-MLE have observed the effectiveness of their medium of instruction through the use of storybooks (Balacano, 2020), the use of other books for classroom activities or exercises (Kolman, 2019), the use of references and dictionaries (Trujillo, 2020), and the use of various techniques such as singing or praying at the start of class in MTB-MLE language (Abrea, Ortua, \& Robles, 2020).

Use of Technology in Teaching

The use of instructional technology in MTBMLE classes ensures students' participation and learning. According to Abdulrahaman et al. (2020), this technology, particularly multimedia, has an interactive component that enables people to share information or ideas via digital and printed media. The use of technology engages students in the learning process, improves their grades, and allows them to complete assignments more efficiently than with traditional teaching methods (Nawzad, Rahim, \& Said, 2018). They become engaged in class despite the challenges associated with learning MTB-MLE lessons. Applications or tools based on technology (such as 
audio-visuals, PowerPoint presentations, or blackboards) are critical for learning and should be used in teaching.

\section{Consultation with another Teacher}

Teachers consult with and collaborate, mainly seasoned and experienced in teaching MTB-MLE. According to Geeraerts et al. (2018), each teacher learns differently from their colleagues. Innovative teaching methods and ICT skills are primarily acquired from younger colleagues, whereas practical information, classroom management skills, selforganization, and community building are acquired from older colleagues. Additionally, coworkers provide teachers with perspectives on teaching and teaching methods. According to Dias et al. (2017), teachers in their first year of teaching may experience stress, a lack of appropriate support, and anxiety, resulting in an unwillingness to manage students' academic aspects of education. Novice teachers overcome obstacles with the assistance of more experienced colleagues. Consultation with their colleagues is extremely beneficial in alleviating the fear and confusion associated with teaching MTB-MLE.

Table 3

Key Themes and Ideas Related to the Insights or Realizations of Teachers who Teach MTB-MLE that can be Shared with the Academic Community

\begin{tabular}{|l|l|}
\hline \multicolumn{1}{|c|}{ Major Themes } & \multicolumn{1}{c|}{ Core Ideas } \\
\hline $\begin{array}{l}\text { Importance of MTB-MLE in } \\
\text { students' learning }\end{array}$ & $\begin{array}{l}\text { - Developing students' self-confidence. } \\
\text { - Developing students' ability to think and express themselves without fear of } \\
\text { using Bisaya. }\end{array}$ \\
\hline $\begin{array}{l}\text { A need for the development } \\
\text { of instructional materials }\end{array}$ & $\begin{array}{l}\text { - Proposing to have a curriculum writer from Region XI. } \\
\text { - Using the same content language in the Teacher's Guide and Student Learning } \\
\text { Materials } \\
\text { - Suggesting of a review to the policymakers to use language familiar to the area } \\
\text { or region. }\end{array}$ \\
\hline $\begin{array}{l}\text { Teachers' readiness to teach } \\
\text { - Preparing for daily lessons, especially in MTB-MLE. } \\
\text { - Using the language in the class and as a medium of instruction. } \\
\text { - Reading regularly the lessons and referring to the dictionary to know the } \\
\text { correct terminology to be taught. } \\
\text { - Preparation of more examples and other instructional materials. }\end{array}$ \\
\hline
\end{tabular}

Insights or Realizations of Teachers Teaching MTBMLE to be Shared with the Academic Community As reflected in the responses of the participants, the following were the major themes that emerged: (1) Importance of MTB-MLE in students' learning, (2) a need for the development of instructional materials, and (3) teachers' readiness to teach.

\section{Importance of MTB-MLE in Students' Learning}

When implemented and assisted properly, participants recognize the benefits of the MTB-MLE curriculum and its high probability of success if the language used is appropriate for the subject area. Gaining students' confidence whenever they use MTBMLE as a mode of communication within the school is a critical insight they shared. The use of MTB-MLE increased students' ability to share knowledge, increased class interaction, increased students' inquisitiveness, and increased students' ability to learn faster because difficult lessons were simplified (Gaylo,
2020). Additionally, participants stated that students gained a deeper understanding of the lesson, participated actively in class, freely expressed their ideas, increased and strengthened their self-confidence, and improved their academic ability (Aliab, Prudente, \& Aguila, 2018).

\section{A need for the Development of Instructional Materials}

The Department of Education (DepEd) must continue to develop dependable teaching materials that will guide teachers' daily instruction in indigenous cultural languages. The language used is hoped to be the actual spoken language in the Davao region, as Sinugbuanong Binisaya is not a functional language in the area. It is critical to include authors from the region in localizing teaching materials and the orthography of the localized language. Additionally, students are accustomed to new concepts and abilities and can readily connect. It emphasizes that learning will be 
complete only when students develop a strong bond in their native language and culture (Mangila, 2018).

Teachers should supplement their lack of teaching materials with adequate textbooks and other instructional materials. This is a significant factor in inconsistencies in cultural and educational contexts. The Department of Education must establish mechanisms to maintain teachers' overall positive behavior and consider their recommendations for more effective MTB-MLE implementation (Agbayani, n.d.). Additionally, they recommended that policymakers conduct a thorough review of the MTB-MLE policy and its performance to have a significant impact on students' knowledge development (Gempeso \& Mendez, 2021).

\section{Teachers' Readiness to Teach}

Teachers' preparedness serves as a shield against any obstacles and difficulties encountered while teaching MTB-MLE. Cabardo (2017) noted that for teaching to be effective, teachers must consider their stated commitment and role in advancing the goals of improving teaching and learning, the student performance process, and all efforts toward academic excellence and higher academic results.

Participants recommended employing strategies and even reading the daily lessons aloud. Trujillo (2020) recommended that teachers strictly enforce the first language as the medium of instruction from the start for students to express their ideas clearly and think without hesitation or self-doubt. Additionally, teachers should provide accurate translations so that students are not perplexed by the concepts presented and easily comprehend unfamiliar words. Additionally, the development and continued improvement of other instructional materials to enhance students' learning became a strategy for addressing teaching difficulties associated with MTB-MLE.

\section{SUGGESTION}

The attitudes and difficulties encountered by public teachers while teaching MTB-MLE demonstrated the existence of implementation issues that must be addressed and improved to benefit students' learning. The study's findings serve as a foundation for evaluating or revising the MTB-MLE curriculum that has been localized or contextualized to the region's language. Additionally, lessons can be taught effectively and quickly understood if the lack of or inadequacy of instructional materials and technology is addressed, teachers' resourcefulness is bolstered, and effective classroom strategies and techniques are employed.
Local curriculum authors or writers must develop the orthography and grammar of the regional language. This will result in contextualized books, dictionaries, modules, teaching guides, and other materials compatible with contemporary teaching methods such as PowerPoint presentations, multimedia, and video. Additionally, holding monthly meetings, webinars, or seminars to discuss the various strategies available to teachers will assist in addressing the MTBMLE teachers' challenging abilities. Additionally, it is critical to strengthen home-school collaboration and teacher-parent engagement.

\section{CONCLUSION}

Each teacher who teaches MTB-MLE has a unique set of attitudes and problems, adding to the teaching difficulties. Nonetheless, these teachers' shared experiences can be gleaned from the lesson and inspire others to overcome any obstacle, not just for themselves but especially for the students who need assistance in learning MTB-MLE. Sharing teaching techniques enables students to overcome the barriers within the four walls of the classroom. Additionally, the teachers' insights, particularly their appreciation of MTB-MLE teaching as a guiding statement for the academic community, will hopefully inspire them to continue the well-established goal of developing students' ability over and above the ease of learning in the first language.

\section{REFERENCES}

1. Abrea, A. C., Ortua, E. C. L., \& Robles, R. L. (2020). Experiences of teachers teaching grade 4 pupils with Mother Tongue-Based Multilingual Education (MTB$M L E)$ : inputs to policy development and teacher training for MTB-MLE. Asia Pacific Higher Education Research Journal (APHERJ), 7(1).

2. Abdulrahaman, M. D., Faruk, N., Oloyede, A. A., Surajudeen-Bakinde, N. T., Olawoyin, L. A., Mejabi, O. V., ... \& Azeez, A. L. (2020). Multimedia tools in the teaching and learning processes: a systematic review. Heliyon, 6(11), e05312.

3. Adriano, M. N. I., Franco, N. T., \& Estrella, E. A. (2021). Language-in-education policies and stakeholders' perception of the current MTB-MLE policy in an ASEAN country. Australian Journal of Language and Literacy, The, 44(1), 84-99.

4. Agbayani, R. S. The MTBMLE Policy: Attitudes Among Teachers on the Ground Annie Mae C. Berowa. Asian EFL Journal, 21(2.3), 123-141.

5. Aliñab, J. M., Prudente, M. S., \& Aguja, S. E. (2018). Teachers' Perceptions on Using MTB-MLE in Teaching Grade 3 Mathematics. Advanced Science Letters, 24(11), 8039-8042. 
6. Asfaha, Y. M. (2020). Multilingual language policy discourses and superdiversity at the peripheries: exploring language policy and practice in Eritrea. Journal of Multicultural Discourses, 15(4), 404421.

7. Bacalla, L. A. (2020) PAGTATAYA NG MTB-MLE: TUGON SA PAGPAPAUNLAD NG IMPLEMENTASYON NG K TO 12 KURIKULUM.

8. Balacano, R. C. (2020). Juan Tama, Mother TongueBased Multilingual Education (MTB-MLE) Storybooks: Their Effectiveness on Pupils' Learning. KnE Social Sciences, 1-5.

9. Ball, J., \& Smith, M. (2021). Essential components in planning multilingual education: a case study of Cambodia's Multilingual Education National Action Plan. Current Issues in Language Planning, 1-21.

10. Cabardo, J. R. (2017). Level of Readiness and Instructional Competence of Grade I and II Teachers in the Mother Tongue-Based Multilingual Instruction. Available at SSRN 2761423.

11. Creswell, J. W., \& Poth, C. N. (2016). Qualitative inquiry and research design: Choosing among five approaches. Sage publications.

12. DepEd. (2012, February 17). DepEd order No. 16, s. 2012: Guidelines on the implementation of the mother Tongue-Based multilingual education (MTB-MLE). https://www.deped.gov.ph/2012/02/17/do-16-s-2012guidelines-on-the-implementation-of-the-mother-tonguebased-multilingual-education-mtb-mlel

13. Dias-Lacy, S. L., \& Guirguis, R. V. (2017). Challenges for New Teachers and Ways of Coping with Them. Journal of Education and Learning, 6(3), 265272.

14. Dumetz, J., \& Vishnyakova, A. (2021). Unexpected Disadvantages of a Simultaneous Quadrilingual Upbringing, a Case Study. International Journal of Teaching and Education

15. Gaylo, P. J. B. (2020). Implementing Mother Tongue Based-Multilingual Education (Mtb-Mle): Outcomes And Challenges. Review, 148.

16. Geeraerts, K., Tynjälä, P., \& Heikkinen, H. L. (2018). Inter-generational learning of teachers: what and how do teachers learn from older and younger colleagues?. European Journal of Teacher Education, 41(4), 479-495.

17. Gempeso, H. D. P., \& Mendez, J. D. S. (2021). Constructive Alignment of Mother Tongue-Based Multilingual Education (MTB MLE) Language Policy Implementation to the Practices of a Multilingual Classroom. English Language Teaching Educational Journal, 4(2), 125-137.

18. Kolman, R. M., \& San Carlos City, P. (2019). Current Status and Challenges of Mother Tongue Teachers in Pangasinan Public Elementary Schools.

19. Sumalinog, G. G. (2018). Mother Tongue Implementation in the Philippines: What Do Parents Say. International Journal of Science and Research (IJSR), 8(6), 911-915.
20. Tonio, J., \& Ella, J. (2019). Pre-service Teachers' Attitudes towards the Use of Mother Tongue as Medium of Instruction. Asian EFL, 21(2.3), 231-253.

21. Tupas, R., \& Martin, I. P. (2017). Bilingual and mother tongue-based multilingual education in the Philippines. Bilingual and multilingual education, 10, 247-258.

22. Trujillo, J. S. (2020). The use of mother tongue in instruction: Pupil's performance across the years. Globus Journal of Progressive Education, 10(1), 59-67.

23. Llaneta, C. A. C. (2018, February 6). Teaching in mother tongues. https://up.edu.ph/teaching-in-mothertongues.

24. Mangila, B. B. (2018). Are IMs Culturally Relevant?" A Critical Analysis of the Instructional Materials Used in Mother Tongue-Based Multilingual Education Program. Asia Pacific Journal of Multidisciplinary Research, 6(2), 53-60.

25. Mažeikienè, V. (2019). Translation as a method in teaching ESP: An inductive thematic analysis of literature. Journal of Teaching English for Specific and Academic Purposes, 513-523.

26. Medilo Jr, C. G. (2016, October). The experience of mother tongue-based multilingual education teachers in Southern Leyte, Philippines. In International Forum Journal (Vol. 19, No. 2, pp. 64-79).

27. Namanya, S. J. C. (2017, December). The effects of mother tongue-based multilingual education on the English literacy of children in Silang, Philippines. In International Forum Journal (Vol. 20, No. 2, pp. 160177).

28. Nawzad, L., Rahim, D., \& Said, K. (2018). The effectiveness of technology for improving the teaching of natural science subjects. Indonesian Journal of Curriculum and Educational Technology Studies, 6(1), 15-21.

29. Ohyama, M. (2018). Japanese mother tongue program in an international school: A case study (Doctoral dissertation, Fordham University).

30. Parba, J. (2018). Teachers' shifting language ideologies and teaching practices in Philippine mother tongue classrooms. Linguistics and Education, 47, 27-35.

31. Tonio, J., \& Ella, J. (2019). Pre-service Teachers' Attitudes towards the Use of Mother Tongue as Medium of Instruction. Asian EFL, 21(2.3), 231-253.

32. Trujillo, J. S. (2020). The use of mother tongue in instruction: Pupil's performance across the years. Globus Journal of Progressive Education, 10(1), 59-67.

33. Tupas, R., \& Martin, I. P. (2017). Bilingual and mother tongue-based multilingual education in the Philippines. Bilingual and multilingual education, 10, 247-258.

34. Velez, M. G. B., Cabrera, M. L. T., Don, A. Q. M., \& Real, V. C. (2019). GRADE ONE LEARNERS' PERFORMANCE ON MOTHER TONGUE-BASED MULTILINGUAL EDUCATION. The Pillar-Research, 52. 